\title{
As Cidades Fazem-se por Dentro Desafios de etnografia urbana
}

\author{
Graça Índias Cordeiro*
}

\begin{abstract}
Resumo: Este artigo discute um problema central na etnografia urbana: a delimitação de um terreno de pesquisa que acaba por coincidir, em larga medida, com a delimitação do próprio objecto de estudo. Numa primeira parte, faz uma retrospectiva histórica sobre este problema, desde a Escola de Chicago até à institucionalização da antropologia urbana nos EUA nos anos 1970 e, numa segunda parte, exemplifica com tipos de recorte etnográfico usados em investigações passadas. A relação entre a parte da cidade etnograficamente apreendida e a totalidade urbana é aqui analisada, utilizando noções intermédias ou planos intermédios de análise sugeridos por alguns autores, como possibilidades criativas que abrem janelas sobre a cidade, ajudando a descrevê-la e a pensá-la numa perspectiva etnográfica.
\end{abstract}

Palavras-chave: Etnografia urbana; Cidade relacional; Micro e macro; Bairro; Sociabilidade.

\section{Apresentação}

Este texto é uma versão ligeiramente modificada da lição de síntese das minhas provas de agregação em Antropologia Urbana que tiveram lugar no ISCTE em Maio de 2004 ${ }^{1}$. Debruça-se sobre um problema central na investigação etnográfica em contexto urbano: o da selecção das unidades de observação, ou, por outras palavras, o da escolha de um terreno que acaba por ser, em larga medida, o da definição do próprio objecto de estudo ${ }^{2}$. Este problema, crucial na etnografia urbana, merece uma atenção muito particular, uma vez que as suas unidades de estudo e limites da indagação no terreno não são definidos rigidamente, constituindo a identificação das entidades observáveis, já em si própria, parte substancial do próprio processo de investigação etnográfico que tem de desentranhar a forma e os limites dos sistemas sociais e dos mundos culturais. No processo etnográfico, o perímetro das descobertas ñ̃a se estabelece de antemão, revelando- -se pouco a pouco à medida que o trabalho de campo avança (Valentine, 1972: 179).

No caso das cidades, a mobilidade, a segregação de domínios de vida social, a sobreposição e multiplicidade de escalas e níveis organizacionais constituem desafios sérios à própria capacidade etnográfica, no sentido de conseguir percepcionar e, nalguns casos, isolar unidades de interacção, com projecção socioespacial ou não, que possibilitem que esse misto de inserção social, observação, recolha documental e entrevista informal - a que chamamos de etnografia - possa ocorrer.

Em termos mais genéricos, podemos dizer que esta questão se insere numa discussão de âmbito mais alargado, já antigo no interior da antropologia urbana, expressa, desde os anos 70, na dicotomia simplificada entre uma antropologia $d a$ cidade e uma antropologia na cidade (Fox, 1972) e que já questionava as próprias possibilidades heurísticas

\footnotetext{
*ISCTE-IUL, Instituto Universitário de Lisboa. graca.cordeiro@iscte.pt

${ }^{1}$ Agradeço aos membros do júri que discutiram comigo esta lição: Joan Josep Pujadas, João Pina Cabral, Raul Iturra, Vítor Matias Ferreira; e, também, aos colegas que, posteriormente, comentaram e sugeriram melhorias ao texto apresentado: António Firmino da Costa, Tim Sieber, Gilberto Velho, Frédéric Vidal, Rita d'Ávila Cachado, Heitor Frúgoli Júnior e José Guilherme Magnani.

${ }^{2}$ Muito embora as diferenças entre antropologia e sociologia estejam longe de ser claras, pelo menos no que se refere ao estudo das realidades urbanas, o meu ponto de vista é o da antropologia. A este propósilo, julgo que vale a pena referir a excelente síntese de Jacques Hamel (1997: 93 e seguintes), quando postula a necessidade de se definir os objectos de estudo em função da disciplina de referência, no plano prático: " $\bullet$ objecto de estudo é sempre habilado por um ponto de vista, o da disciplina que o preconiza, e, consequentemente, deve ser formulado nos termos que o exprimem, de um modo irrefutável" (95)
} 
da antropologia urbana (Cordeiro, 2003). Problema que se pode traduzir na seguinte questão: como é que o estudo de partes ou fragmentos de cidade se pode transformar em conhecimento da cidade?

$\mathrm{O}$ texto organiza-se em duas partes. A primeira perspectiva historicamente o problema, relembrando alguns dos momentos que marcaram avanços importantes no desenvolvimento da análise antropológica sobre a cidade e o urbano, e que contribuíram para um amadurecimento desta reflexão 'urbanológica', desde a Escola de Chicago até aos anos da institucionalização da designada 'antropologia urbana', nos EUA, ao longo das décadas de 1970 e 80 para, de seguida, o problematizar de uma forma mais detalhada. É a relação entre a parte da cidade observada, etnograficamente apreendida, e a totalidade urbana, seja ela concebida como zona, cidade, metrópole, que é aqui analisada. Como bem afirma Michel Agier: na cidade, os conhecimentos retirados desta pesquisa [etnográfica] são inevitavelmente parciais, e só abrangem a totalidade urbana através de procedimentos de análise: metonímias (a cidade é a rua), metáforas (a cidade é uma selva ou um mosaico), comparações (que conduzem, por exemplo, a uma tipologia cultural dos bairros de uma cidade) e diálogo interdisciplinar (encaixe das escalas do etnólogo com as da economia, da macro sociologia, da política urbana, etc.) ${ }^{3}$ (Agier, 1996: 35) As noções intermédias que este autor identifica, numa retrospectiva histórica com sabor prospectivo ou os planos intermédios, sugeridos por José G. Magnani (2002) que permitem distinguir padrões e regularidades que constituem totalidades providas de significado para os actores, são possibilidades muito sugestivas de análise urbana que permitem abrir janelas sobre a cidade, ajudando a descrevê-la e pensá-la numa perspectiva etnográfica.

A segunda parte, mais claramente empírica, exemplifica com investigações que fazem parte do meu próprio percurso biográfico, algumas possibilidades de recortes etnográficos que me levaram a identificar territórios, redes e expressões de sociabilidade como "lugares" ou "entidades" de nível intermédio.

Esta apresentação tem como principal finalidade falar, de forma relativamente simplificada e aces- sível, respeitando o tom coloquial e leve que uma aula deve ter, de problemas que não se esgotam nesta breve síntese, como, por exemplo, a relevância dos estudos de caso, o valor explicativo das descrições ou a explicitação da relação entre escalas de observação e de análise. Neste sentido, algumas destas questões, muito embora sejam cruciais para o processo de conhecimento etnográfico da cidade e do urbano não são suficientemente aprofundadas como mereciam.

\section{Entre terrenos e objectos, a etnografia urbana}

\section{Breve perspectiva histórica}

Gostava de começar por esclarecer que o título se inspira num texto de José G. Magnani (2002) cujo objectivo é o de conjugar duas linhas de reflexão contrastantes sobre o urbano e a cidade: uma, clássica, que tem tomado a cidade como objecto, olhando-a de fora e de longe, outra etnográfica, mais centrada em "partes" ou "fragmentos" de cidade, que a tem olhado de perto e de dentro (11). Tal como o autor deste texto tenho a convicção de que esta última abordagem abre para formas de compreensão aprofundada do «fenómeno urbano» no seu conjunto, tanto no que se refere à pesquisa da dinâmica cultural como das formas de sociabilidade nas grandes cidades e metrópoles contemporâneas (11).

Uma valorização excessiva do indivíduo - e, consequentemente, da individualização que, no plano da vida social, tem acompanhado o processo de urbanização ao longo dos dois últimos séculos - tem constituído, de facto, um dos temas fortes de um certo tipo de análise sobre as cidades e metrópoles contemporâneas, que, de acordo com o autor citado, tem enfatizado os seus aspectos desagregadores, olhando-a de fora e de longe. Não me refiro aqui apenas ao indivíduo calculista, interesseiro, anómico, blasé, na acepção que os autores clássicos lhe deram - veja-se Simmel, Tonnies, Durkheim, Marx.... - mas também esse individualismo contemporâneo que reveste formas particulares na sua manifestação, de acordo com versões mais modernas (e pós-modernas) que insistem em olhar para

\footnotetext{
${ }^{3}$ Este artigo está incluído em um livro recente de Michel Agier Esquisses d'une anthropologie de la ville (2009) cuja tradução portuguesa será publicada no Brasil no início de 2011.
} 
as grandes cidades como lugares de fragmentação sociocultural, de rupturas a vários níveis, de solidão e rarefacção de contactos sociais mais duradouros, de "exclusão social", de "não-lugares", de redes virtuais, configurando formas de comunicação mais superficiais e fugazes, tendentes à dissolução de certas formas de sociabilidade entendidas como mais "comunitárias".

É a confrontação directa do indivíduo com a cidade (Magnani, 2002: 25) que dá esta sensação inevitável de anonimato, fragmentação, desordem. $\mathrm{O}$ que a etnografia urbana tem procurado, ao longo daquilo que já se pode considerar a sua "pequena história" particular na construção de um tipo de conhecimento urbano, tem sido a focalização justa, a partir de dentro, não tão próxima que sobrevalorize o particularismo individual, reforçando esta visão atomizada da vida urbana (como se o indivíduo estivesse só), nem tão longe que resulte num recorte demasiado abrangente onde a inserção do indivíduo em grupos e redes se perca, acabando por ficar desprovido de sentido e de inteligibilidade para o observador (idem). É a medida certa deste enfoque tão próprio da antropologia que tem permitido leituras e interpretações do viver urbano, relativamente invisível, tanto do lado das práticas de sociabilidade como da produção cultural, que enquadram certas vivências colectivas e individuais que escapam a outros tipos de abordagens.

Um primeiro momento a assinalar, fundador deste olhar próximo e questionador da cidade, corresponde ao olhar que a "Escola de Chicago" deitou sobre a cidade. É já consensualmente reconhecido que os etnógrafos-sociólogos que, nos princípios do século XX (anos 20,30, sobretudo) estudaram aprofundadamente essa grande cidade americana marcaram os inícios dos estudos urbanos, tendo emancipado a cidade, promovendo-a de produto ou lugar a factor determinante das dinâmicas sociais, para utilizar os termos de Amália Signorelli (1999:68). Sob a orientação decisiva de Robert Park, um conjunto de autores são hoje legitimamente considerados fundadores da investigação urbana nas ciências sociais não apenas pela sua abordagem etnográfica das realidades urbanas, até certo ponto pioneira, na época, (e poderíamos a este propósito relembrar outras investigações anteriores, como as de Le Play, apenas para dar um exemplo), mas, fundamental- mente, pelo quadro teórico de questionamento da própria cidade que marcou profundamente estes trabalhos.

O contexto social da cidade em acelerado e intenso crescimento terá contribuído para a fertilização das teorias que então se desenvolveram, a par dos movimentos de reforma social e da formação sociológica europeia de parte destes autores. A identificação, no interior da cidade, de áreas segregadas é, afinal, a descriminação de lugares intermédios de vida social e cultural, a meio caminho entre o indivíduo solitário e a cidade-total (essa cidade grande, densa e heterogénea) nível intermédio este que permite procurar o sentido das classificações socioespaciais correntes (Agier, 1996). Estes primeiros olhares sobre o território amplo de uma grande cidade em crescimento - entendida como cidade-mosaico ${ }^{4}$ - permitiram, assim, inserir o indivíduo em espaços intermédios de vida social - áreas naturais, regiões morais (R. Park) - que ajudaram ao aprofundamento de um conhecimento próximo e de dentro, um pouco como se de tribos se tratassem, que levaram à publicação de um conjunto de etnografias urbanas que ainda hoje são referência e fonte de aprendizagem para sociólogos, antropólogos, geógrafos, urbanistas.

Segundo momento a assinalar na história da etnografia urbana: a chamada Escola de Manchester e, muito particularmente, as investigações feitas sobre cidades da ex-Rodésia do Norte, no âmbito do Rhodes Livingstone-Institut. Aqui, surge um novo olhar sobre a cidade, inspirada nas noções de situação (Evans-Pritchard, 1940) e de rede social (Barnes, 1954) que, de certa forma, desespacializa a pesquisa urbana, libertando o observador do constrangimento monográfico habitual da etnografia (Agier, 1996:44). No primeiro caso, deixam de ser os limites espaciais que definem a situação, e passam a ser os da interacção. No segundo caso, análise de redes sociais, o etnólogo urbano tornase completamente móvel apoiando-se em diferentes situações para 'ver' e 'seguir' redes sociais a operarem in situ. É neste momento que faz todo o sentido o princípio da articulação das situações de vida dos citadinos que permitem reconstituir a coerência das redes em diferentes ocorrências da vida urbana (Agier, idem: 50). Com estes trabalhos, que constituem a incursão mais importante da antropologia

\footnotetext{
${ }^{4}$ Ulf Hannerz contrapõe a esta imagem a de cidade-caleisdoscópio (1980).
} 
social britânica em meio urbano (Hannerz, 1980) o olhar sobre a cidade passa a centrar-se mais na relação e menos no indivíduo.

E chegamos aos anos 70 do século Xx, momento em que se institucionaliza o campo da antropologia urbana, com início nos EUA. Retrospectivamente, podemos considerar este terceiro momento - que incorpora a 'tradição' de Chicago e de Manchester - como um momento fundador de uma nova abordagem da cidade e dos seus mundos, baseada numa perspectiva etnográfica e antropológica em franco diálogo com a sociologia, a geografia, a economia política, entre outros (Hannerz, 1980).

De entre as várias obras de antropologia urbana que, ao longo das décadas de 1970 e 1980 são publicadas, vale a pena referir três, pelas propostas que contém de recortes de vida urbana, reveladoras de modos de conceber a cidade e de nela investigar, sob uma perspectiva etnográfica (Eames e Goode, 1977; Hannerz, 1980 Gulick, 1989). Com intencionalidades e objectivos diferentes, tais propostas são extremamente simples e têm a enorme vantagem de se complementarem, no parcelamento que sugerem desses universos densos, complexos, múltiplos, incertos, que são as cidades. Tomo-os aqui como pontos de partida para uma reflexão sobre a organização material e simbólica das cidades e da vida urbana contemporânea.

Uma das primeiras sistematizações sobre o modo como os estudos antropológicos seleccionaram partes ou componentes da cidade encontra-se na primeira destas três obras e que bem pode ser considerada um dos mais completos manuais de antropologia urbana de sempre: Anthropology of the city. An introduction to Urban Anthropology, da autoria de Edwin Eames e Judith Granich Goode, publicado em 1977 (Englewood Cliffs, New Jersey: Prentice-Hall). De acordo com uma revisão bibliográfica intensiva ${ }^{5}$, os autores classificam um vasto conjunto de etnografias urbanas, publicadas até aquela data, em três grandes conjuntos, segundo o tipo de unidade etnográfica eleita: aquelas que se centraram preferencialmente em unidades primárias ou pessoais (primary or personal units, pp. 117-159), sendo as mais importantes as baseadas em redes sociais, laços de parentesco e grupos domésticos; em componentes urbanas maiores (corporate or major urban components, pp. 160 -215) compostas por grupos baseados num território

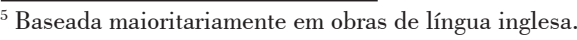

residencial comum, numa cultura comum de origem e num papel comum na divisão de trabalho; e em unidades de integração (units of integration, pp. 216-254), localizadas espacial ou temporalmente, compostas por instituições formais ou informais e situações temporais ou espaciais que juntam diferentes segmentos de população urbana segundo certos mecanismos integradores.

Ulf Hannerz, por seu lado, na conhecida obra Exploring the City. Inquiries Toward an Urban Anthropology(New York: Columbia University Press) de 1980, sugere uma divisão da vida social urbana em cinco grandes domínios, compreendendo cada um deles uma multiplicidade de papéis: lar e parentesco, abastecimento, lazeres, vizinhanças e tráfego (household and kinship, provisioning, recreation, neighboring, traffic, pp. 102-110) Segundo ele, dois destes domínios são particularmente importantes na vida citadina: o do abastecimento e do tráfego. Vale a pena acrescentar que, para este autor, uma antropologia que se queira $d a$ cidade e não apenas na cidade deverá olhar as cidades como estruturas sociais de domínios múltiplos, com uma particular atenção às formas e graus de inter-relações entre papéis, não só no interior dos domínios, como entre eles (ob. cit: 142). Segundo ele, a cidade deve ser olhada como o contexto da observação etnográfica, um "pano de fundo" sobre o qual se analisam casos particulares, tão diversificados quanto possível, de modo a deixar transparecer as conexões e cruzamentos (redes de redes) que compõem a cidade.

Finalmente, John Gulick, em The humanity of cities. An introduction to urban societies(Granby, Massachusetts: Bergin and Garvey Publishers, Inc.) de 1989, identifica dois grandes níveis de conexões sociais nas grandes cidades, de microescala (small-scale connections, p. 151) e de macroescala (large-scale connections, idem), baseando-se o primeiro em conexões pessoais (de base territorial, como bairros e vizinhanças, ou dispersas, em rede), o segundo em subculturas (182) de tipo universal (étnicas, de classe social, de ciclo de vida) ou em estilos de vida colectiva.

De um modo algo simplificador, pode-se sintetizar esta brevíssima abordagem histórica sobre os vários modos como a cidade tem sido recortada etnograficamente, como um movimento que, progressivamente, tem incorporado vectores e planos de complexificação, sob várias escalas de observação e 
de análise (temporais, espaciais, sociais) no "olhar" sobre essa entidade inacessível empiricamente - a cidade. Inspirando-me no texto de Michel Agier, quase que poderia dizer que o sentido desta reflexão que tem ajudado a descriminar, classificar, categorizar os planos intermédios de vida social em que a etnografia opera (mais adiante veremos como...) se tem construído contra a sinonímia entre espacial, social e cultural, que é o legado mais embaraçoso da etnologia clássica (1996: 57).

\section{A cidade recomposta: do indivíduo ao contexto}

Uma das críticas, frequentemente implícitas, relativamente à antropologia urbana, refere-se à ênfase desequilibrada que esta disciplina tem posto no estudo das "partes das cidades" esquecendo a cidade em si. Efectivamente, esta relação tem sido explicitada em antropologia, uma vez que o contexto cidade lhe coloca problemas novos relativamente à sua base de conhecimento: o trabalho de campo etnográfico, cujos conhecimentos estão enraizados em espaços de interconhecimento de nível micro-social. Como conciliar, então, uma reflexão e uma metodologia centrada no indivíduo-em-relação, inserido em espaços socialmente e culturalmente heterogéneos, sem abandonar as suas próprias questões fundadoras relativas à organização social e à unidade cultural das populações?, pergunta Michel Agier, no seu livro L'invention de la ville (1999).

Tal como este e outros autores sugerem, o ponto de partida deve ser o dos lugares em que os indivíduos se inserem, que deixam ver a vida citadina pelo lado de dentro, fazendo surgir uma imagem de cidade mais familiar, mais relacional, mais cultural, como produto da observação antropológica: feita da descrição das práticas, das situações e das interacções de citadinos diferenciados. Trata-se de uma opção metodológica de base, que tem como objectivo, não contrapor uma nova definição de cidade em termos substanciais, mas sim permitir descobrir as formas urbanas que se vão inventando, criando, produzindo e sedimentando - resistindo e emergindo - independentemente das formas urbanas, materiais e institucionais de cada cidade particular... Pour retrouver la ville, oublions-la d'abord... (1999: 9).

Este é o ponto de vista da etnografia urbana, baseado na percepção do concreto vivido, capaz de descobrir formas inesperadas de invenção social, sobretudo nas cidades que são ambientes particularmente propícios a tais desenvolvimentos e que concentram cerca de $2 / 3$ da população mundial. Nunca será demais relembrar que a grande maioria desta população vive formas de urbanização precária, informal e ilegal, desenvolvendo práticas urbanas plurais que acabam por representar a fatia mais relevante da experiência citadina. Estas cidades reais já não são as herdeiras directas do urbanismo medieval nem das utopias urbanísticas e, nas suas formas inéditas de urbanização, constituem, sem dúvida alguma, um dos maiores desafios à antropologia urbana tanto do ponto de vista científico quanto político (Agier, 2008).

Temos, portanto, a cidade olhada a partir do indivíduo - como ponto de partida. Que não está só, que se insere em certos espaços, grupos, redes, desde os mais informais aos mais institucionais, em várias escalas e planos. É este nível intermédio, identificado por vários autores, tanto em olhares retrospectivos sobre a Escola de Chicago, com a noção de região e a Escola de Manchester, com as noções de situação e de rede (Agier, 1996) como em propostas concretas de etnografia urbana (Magnani, 2002), que nos pode ajudar a perceber a originalidade e especificidade do ponto de vista etnográfico, que permite captar determinados aspectos da vida urbana que, sob enfoques mais macro, passariam desapercebidos. A perspectiva antropológica (etnográfica) tem a vantagem de evitar a dicotomia entre o indivíduo e as megaestruturas urbanas, permitindo ver as múltiplas possibilidades e alternativas que a vida cosmopolita propicia (...) grupos, redes, sistemas de troca, pontos de encontro, instituições, arranjos, trajectos e muitas outras mediações por meio das quais aquela entidade abstracta do indivíduo participa efectivamente, em seu quotidiano, na cidade (Magnani, 2002: 17).

Um olhar de perto e de dentro, que é diferente de um outro olhar de passagem, cujo fio condutor são as escolhas e os trajectos do investigador ${ }^{6}$, uma

\footnotetext{
${ }^{6}$ É assim que o autor caracteriza esta modalidade de conhecimento de passagem, «ela consiste em percorrer a cidade e seus meandros observando espaços, equipamentos e personagens típicos com seus hábitos, conflitos e expedientes, deixando-se imbuir pela fragmentação que a sucessão de imagens e de situações produz. O relato final, geralmente na forma de ensaio, termina por expressar essa experiência por meio do uso de metáforas que serão tanto mais sugestivas quanto maior a criatividade do analista e o leque de relações que estabelecer: "hibridização", "porosidades", "territorialidades flexíveis", "não-lugares", "configurações espaço-temporais", "paisagens disjuntivas" e outras» (ob. cit.: 18)
} 
vez que é a partir dos arranjos dos próprios actores nos diferentes domínios da vida social que o antropólogo constrói o seu conhecimento, investindo em ambos os pólos da relação: as práticas dos actores e o contexto em que essas práticas se desenvolvem, entendido como parte constitutiva do próprio recorte de análise (ob. cit. 18). Para Magnani dois procedimentos impõem-se ao antropólogo urbano no modo de organizar os seus dados etnográficos, muitas vezes percebidos como fragmentários e dispersos: por um lado, o pressuposto da totalidade e, por outro, a identificação de famílias de categorias. Vejamos um pouco mais de perto o que significam estes dois procedimentos.

A comunidade, a aldeia, tem sido um dos recortes clássicos da etnografia ${ }^{7}$. Contudo, em contextos urbanos, não se podem encontrar facilmente equivalentes a esta "forma social" onde o espaço e a unidade social muitas vezes coincidem. Mas dizer isto não significa que não seja necessário procurar outro tipo de recortes que operam em várias planos e escalas (mais restritos e mais amplos, por vezes em casca de cebola). Efectivamente, a pesquisa etnográfica obriga à identificação de recortes, de fronteiras simbólicas que permitam a delimitação do caso em análise (e, muito concretamente, a unidade de observação) de um modo não arbitrário no sentido em que sejam reconhecidas pelos indivíduos ou grupos investigados como "totalidades" que enquadrem a sua vida concreta e lhes façam sentido. Circunscrever uma entidade - um lugar, uma situação, uma rede social - é um passo fundamental para a poder estudar. A descrição desempenha aqui um papel fundamental (eu diria, até: o papel fundamental), no sentido de fazer ressaltar o que pode constituir o próprio objecto de estudo. O recorte circunscrito é a base do estudo de caso, em profundidade, com uma preocupação de totalização ao nível da observação, da reconstrução e da análise dos factos observados (Hamel, 1997: 80). Convém, pois, não confundir o modo como esta "totalidade" é vivida e percebida pelos "nativos" e o modo como é percebida e interpretada pelo antropólogo: para os primeiros, é o contexto da experiência, para o segundo, é chave de inteligibilidade e princípio explicativo (Magnani, 2002: 20).

A cidade, noutro plano, constitui um dos pólos da relação com estas totalidades, que podem ser mais ou menos espacializadas. Por exemplo, a noção de pedaço, usada por Magnani no seu estudo sobre práticas de lazer em S. Paulo (1984) refere-se a um espaço intermediário entre o privado e o público, onde se desenvolve uma sociabilidade básica, mais ampla que a familiar e mais densa, significativa e estável do que as relações formais (2002: 20), possuindo por isso dois elementos, um de ordem espacial, outro de ordem social, na forma de redes de relações (idem). Esta é uma das categorias "nativas" utilizadas pelo autor para exemplificar o modo como o trabalho do etnógrafo se baseia, em grande medida, na identificação de termos e "arranjos" nativos, descrevendo-os e trabalhando-os num plano mais geral, relacionando-os e descobrindo teorias. Certas práticas culturais, por um lado, e a cidade, por outro, ajudam a delimitar as unidades de análise da etnografia - para conseguir isso, é necessário que a lente não se aproxima demasiado (dando a imagem de uma excessiva fragmentação em torno do indivíduo) nem tão longe que não seja capaz de encontrar as categorias e as totalidades relevantes e significativas para cada um dos indivíduos e contexto de interpretação para o investigador. É, precisamente, neste planos intermédios de inserção individual que a etnografia deve buscar a forma como a cidade se produz, ao nível mais microscópico e invisível. Insisto novamente no papel da descrição, traduzida numa escrita clara, que vai coordenando as categorias do investigador com as que decorrem das informações do terreno (Hamel, ob. cit.: 84).

Para sintetizar este ponto, pode-se afirmar que tais planos, níveis ou noções intermédios - as noções são, aqui equivalentes - constituem a própria possibilidade de investigação etnográfica em contexto urbano. A este propósito, não posso deixar de relembrar dois autores que, no meu próprio percurso de investigação, constituíram fonte de inspiração, pela utilização de conceitos similares: Gilberto Velho, antropólogo, com as suas reflexões sobre certas noções intermédias nas sociedades contemporâneas - como província de significado (Velho, 1981, 1994) e António Firmino da Costa, sociólogo, com a noção de quadro de interacção local, desenvolvida em torno da sua pesquisa sobre o bairro de

\footnotetext{
${ }^{7}$ Lembro aqui a célebre definição de aldeia transmontana de Orlando Ribeiro: «A aldeia não é aqui apenas um agrupamento de população, mas uma forma de vida social a que dá coesão um passado comunitário de que se encontram muitos vestígios» (1963: 86)
} 
Alfama (1999). O que gostaria de explicar um pouco melhor, numa segunda parte deste, exemplificando com dois casos de estudo etnográfico em Lisboa: o jogo da laranjinha e o bairro da Bica.

\section{Conexões, lugares e identidades}

Gostaria, agora, de ancorar esta reflexão teórica e metodológica em duas experiências de investigação que me ajudaram a clarificar algumas opções metodológicas fortemente enraizadas numa perspectiva etnográfica capaz de aceder e construir "por dentro" o conhecimento das cidades. Esta retrospectiva será apresentada, por isso mesmo, ao longo do eixo biográfico em que elas ocorreram, pois correspondem, igualmente, a fases diferentes do meu próprio amadurecimento científico. Relembro, contudo, que a tónica é posta no processo de identificação e definição do objecto de investigação, do terreno, da parcela ou recorte, e não tanto nos resultados alcançados. Muito embora os casos se refiram a investigações de dimensão diferente (tese de mestrado e tese de doutoramento) são comparáveis do ponto de vista do processo de identificação do terreno/objecto. Trata-se, pois, de destacar o próprio processo metodológico da delimitação do objecto/ /terreno e, também, da unidade de observação, inseparável dos avanços teóricos alcançados. Os dois casos complementam-se, do ponto de vista dos recortes delimitados, pois um refere-se a uma prática cultural, de certo modo itinerante, com um "espaço/tempo" próprio, configurador de formas particulares de expressão de sociabilidade, e o outro refere-se a formas de construções identitárias mais confinadas territorialmente.

\section{Expressões de sociabilidade: a "laranjinha", uma ilha na cidade?}

A investigação que fiz para mestrado, entre 1985 e 86, e que acabou por ser sobre um jogo popular de Lisboa (Cordeiro, 1987), começara, de facto, por ser de âmbito muito mais geral, como uma tentativa de incursão num dos domínios de vida social urbana (inspirada na classificação de Ulf Hannerz, em cindo grandes domínios): as práticas de lazer numa cidade. Na sua hipótese inicial, já trabalhada do ponto de vista teórico, a pergunta formulava-se do seguinte modo: como é que as sociabilidades de tempo livre, colectivamente vividas por vizinhos, amigos e parentes num determinado espaço residencial urbano (bairro) contribuíam para a criação de práticas relacionais, laços solidários e códigos culturais, que frequentemente, ajudavam a criar e reproduzir formas particulares de identidade social (de bairro, de género, estilos de vida, etc.)? Questão teórica que, após um curto período exploratório, no sentido de melhor definir o objecto de estudo e seleccionar o lugar para a observação necessária, me levou a fixar nas associações recreativas ou colectividades, como uma boa porta de entrada para a observação deste processo. É claro que estou a saltar um encadeamento de escolhas que fui fazendo, nesse vaivém entre a definição do problema e a selecção da unidade de estudo (pois a relação entre ambas nunca é - ou não devia ser - arbitrária): desde a escolha do bairro de Campo de Ourique (pela visibilidade dos seus lazeres públicos), aos locais de lazer "semipúblicos", observáveis, e no interior deste universo, ainda demasiado amplo, as associações recreativas ou, colectividades (sedes de estruturação e afirmação de grupos locais e pontos de confluência de grupos informais, para além de promotores de vizinhanças e solidariedade entre vizinhos, sobretudo através de actividades lúdicas e festivas) acabando por me deter, finalmente, numa delas, onde uma certa prática lúdica de contornos relativamente "exóticos" parecia sobreviver à história popular urbana da própria cidade. Tal prática lúdica, relativamente nómada, acabou por se tornar no meu caso, alterando radicalmente o problema de partida e o objecto de estudo inicial, afastando-me do desejo de perceber a identidade mais territorializada, em torno das vizinhanças.

Acabei, pois, por me centrar neste jogo inesperado - assumindo desde logo o lado mais imprevisível da etnografia: o jogo da laranjinha, encontrado numa das colectividades em observação ${ }^{8}$. $\mathrm{O}$ acompanhamento da prática do jogo, paradoxalmente, acabou por me levar para fora do bairro, obrigando-me a percorrer um circuito relativamente estabilizado na época - meados dos anos 80 - entre meia dúzia de lugares de jogo, a maioria noutras colectividades, onde me fui familiarizando com o "universo da

\footnotetext{
${ }^{8}$ A "descoberta" deste jogo foi partilhada, ao longo do trabalho de campo, com Luís Pavão que realizou uma exposição de fotografia sobre o tema no Grémio de Instrução Liberal de Campo de Ourique, em 1986.
} 
laranjinha", os seus homens, a sua memória (uma vez que o registo histórico era bastante lacunar), os seus códigos e símbolos, as suas sociabilidades rotineiras - e um determinado estilo de vida e de visão do mundo a ele associado. De uma forma muito resumida, este jogo caracteriza-se pelo seu lado fortemente socializador, exclusivamente masculino, historicamente associado ao universo das sociabilidades de tabernas, criador de laços de solidariedade e partilha de sentidos e modos de ver a cidade e o mundo por parte de uma rede relativamente restrita de homens de idades e status sócio-profissional semelhante, provenientes de ambientes populares da cidade de Lisboa.

O jogo da laranjinha constituía-se, deste modo, como um nó de múltiplos laços sociais, actualizando e reforçando parentescos, vizinhanças, amizades, em torno de espaços, objectos e práticas altamente ritualizadas. De acordo com a proposta de Gilberto Velho, encarei-o, desde logo como uma experiência suficientemente significativa criadora de fronteiras simbólicas (Velho, 1981: 16). Tinha perfeita noção, contudo, de que este segmento de realidade urbana que, estrategicamente, delimitara para tornar possível um trabalho de campo de tipo etnográfico, estava embebido e integrado numa multiplicidade de planos e escalas, desde o nível mais informal ao mais institucional, que não me permitiam ter a ilusão do "real" fechamento das suas fronteiras, mesmo pensando apenas nas simbólicas, uma vez que se efectivavam em planos concretos das práticas quotidianas. Mas, ao mesmo tempo, tinha a segurança de ter contribuído, por via de uma etnografia, para um conhecimento mais aprofundado de uma cidade, resgatando práticas e significados bem presentes que, de outra forma, não seriam conhecidos. No entanto, é bem certo que o simples facto de ter circunscrito a minha observação (e, em certa medida, também o horizonte analítico) a um punhado de homens artificialmente fechados no espaço e no tempo lúdicos da laranjinha, me deixara a sensação de que a cidade me escapara, de algum modo.

Hoje não vejo assim as coisas. Julgo que me situei no plano possível e desejável da etnografia, ou seja, numa rede de jogadores em ambientes de socialização específicos, uma espécie de "micrototalidades de sentido" produzidas através de uma prática lúdica regular que me permitiu definir padrões de sociabilidade transversais a outras práticas e a outros contextos vivenciais. Por outras palavras, situara-me no espaço/tempo do jogo, onde se produzia uma determinada prática cultural, através da qual operava uma rede de relações relativamente estável que produzia códigos de reconhecimento e de comunicação. Sem o ter conseguido formular desta forma, hoje, julgo que aquilo que eu designava metaforicamente como ilha, era, na realidade, um plano intermédio, entre a cidade e o indivíduo, um plano restrito, é certo, mas com um nível de interacção social elevado, que me permitiu percepcionar determinados arranjos colectivos, para utilizar as designações de José G. Magnani, ou, para citar Gilberto Velho, uma província de significado, social e simbolicamente definida.

\section{Redes e territórios: a "Bica", uma aldeia na cidade?}

A escolha do bairro da Bica veio, claro, na continuidade desse interesse pelo tema da vizinhança e da identidade territorial que, de certo modo, havia sido interrompido pela irrupção da laranjinha no meu percurso de investigação. Não me vou demorar a falar do bairro da Bica que, inclusivamente, tem os seus resultados bastante mais publicados do que o anterior (Cordeiro, 1997). Apenas gostaria de destacar que, neste caso, o objecto de estudo se definia em torno do processo de construção social e cultural de um bairro típico de uma cidade, o que significava que, desde o seu início era o bairro e a cidade que estavam em questão, uma vez que o primeiro aparecia como símbolo e emblema da primeira que se revia naquele.

Metodologicamente, a prioridade foi dada à etnografia - o contacto directo e quotidiano com os habitantes de um determinado segmento territorial, ele próprio definido a partir dos vários pontos de vista e categorias nativas sobre o espaço, identificando cuidadosamente limites, inclusões, clivagens e, muito concretamente, os vários bairros em causa, situacionalmente definidos pelos seus habitantes; o enfoque nas sociabilidades festivas, sobretudo a marcha e os arraiais de Junho, que na sua dupla face organizacional e simbólica, constituíam um dos focos privilegiados de análise, na medida em que se situavam claramente na interface entre as vivências endógenas do bairro e a sua produção enquanto ícone para o exterior, num diálogo permanentemente re-activado e re-negociado com a cidade e, muito em concreto, com as instituições do poder local; 
uma atenção muito particular relativamente ao papel das associações locais enquanto mediadoras com as várias instituições locais e supra-locais (Leeds, 1978 [1964]), para além da apropriação de um certo valor patrimonial do bairro.

Mas a busca não se ficou pelo nível etnográfico, que foi complementado com uma pesquisa histórica, arquivística e de imprensa, não apenas no sentido de acrescentar elementos objectivos às memórias sempre circunstanciais dos seus habitantes, como também no sentido de reforçar a dimensão contextual do caso em estudo, a relação inseparável com a cidade, ligação esta necessária para a descrição e, até certo ponto, da explicação, do próprio significado de algumas das práticas e interacções congregadoras de grupos e redes e alianças entre vizinhos, parentes, aliados e amigos, dentro e fora do bairro, que funcionavam como suporte de um conjunto de imagens e representações do bairro e da cidade. Posso, pois dizer que, neste caso, a identificação de uma micrototalidade de nível intermédio para operacionalizar a perspectiva etnográfica primordial - e central, do ponto de vista dos próprios resultados - era sistematicamente acompanhada por um encaixe de escalas locais e inter-locais que me obrigavam a abrir disciplinarmente o próprio objecto de estudo ${ }^{9}$. É aqui que tem toda a pertinência relembrar a noção de quadro de interacção local, descrita e usada por António Firmino da Costa a propósito do seu estudo sobre Alfama. Nas obras publicadas sobre este bairro, o autor elabora finamente este conceito extremamente rico e completo, de nível intermédio (entre a cidade e o indivíduo) que se refere a um conjunto de traços de natureza morfológica, relacional e simbólica que fazem certos bairros, como revelam bem os dois bairros referidos, com o carácter labiríntico da sua malha urbana, formas de relação próxima entre a casa e a rua, razoável densidade de redes sociais locais, os seus sítios de vizinhança, as colectividades, relações de patrocinato e clientelismo, rivalidades intra e inter-bairristas, formas de cultura popular urbana como o fado e as marchas...

Na verdade, só metaforicamente - e desvirtuando a realidade dos factos - seria possível considerar que eu passara do estudo de uma ilha ao estudo de uma aldeia na cidade (apesar dos insistentes ensinamentos dos "meus nativos": isto aqui é como uma aldeia). Em ambos os casos eu conseguira identificar os planos intermédios necessários à realização das etnografias que daí resultaram, que poderiam, noutras épocas, ter sido classificadas como regiões morais (nas palavras de um etnógrafo da Escola de Chicago) situação ou redes sociais, (para um discípulo de Max Gluckman), incorporando sempre essa dimensão fundamental de sentido que me permitia colher e analisar os dados, resultante do confronto permanente das práticas e dos comportamentos com os discursos, as representações, as memórias e o imaginário, dimensões inseparáveis das próprias práticas.

\section{Ao encontro da cidade próxima}

A escolha do recorte etnográfico, como um tipo de recorte empírico em sintonia com a realidade observada surge, assim, como um dos passos mais importantes no processo de investigação etnográfica. A questão inicialmente abordada, sobre o modo como um estudo tão fragmentar das realidades citadinas, de "microsistemas locais" (Weber, 2009) se pode tornar em conhecimento da cidade, levou à identificação de algumas noções intermédias que, teoricamente, têm ajudado a integrar a prática etnográfica, microsocial, pessoal, temporalmente confinada, esse objecto-cidade que, deste ponto de vista, se revela como empiricamente inacessível.

Esta forma de conhecer a cidade, de perto e de dentro, leva-nos, irremediavelmente, à noção de "lugares de vida urbana", que são os contextos ou quadros de identificação local que podem ser entendidos como uma espécie de cidade intermédia, que se situa entre o próximo e o longínquo, entre o caso, que o investigador estuda através de uma relação pessoal construída no terreno, e o contexto, que é simultaneamente espacial, relacional, temporal e que lhe permite desentranhar o significado profundo que se situa algures, entre múltiplas práticas e representações. Os exemplos apontados, entre outros - o estudo de certas práticas colectivas, de bairros, a rua como um recorte quase inexplorado nas nossas cidades (veja-se Cordeiro e Vidal,

\footnotetext{
${ }^{9}$ Nunca é demais relembrar o contributo de Anthony Leeds que sempre insistia na necessidade de modelos analíticos capazes de estabelecer a relação entre os contextos microscópicos da situação etnográfica com os contextos mais amplos que influenciam e são influenciados pela pequena escala - combinando a prática etnográfica com um análise de contexto (Eames e Goode, 1977).
} 
2008) - revelam a cidade próxima que a etnografia procura e trabalha.

A identidade espacial dos citadinos declina-se $e$ constrói-se através de múltiplas escalas territoriais: do mais próximo (casa, prédio, rua, bairro...) ao mais distante (cidade, região, país, continente, mundo) ${ }^{10}$ (Marchal, 2009: 419) A proximidade, o local, apesar dos movimentos de desterritorialização inegáveis na contemporaneidade, continuam a desempenhar um papel importante na construção das identidades citadinas, embora de maneiras diferentes, sob muitos aspectos. Descobrir estas novas modalidades de relação entre o local e o distante constitui, também, um dos objectos da etnografia urbana.
No posfácio do seu livro Fascínio da Cidade, Vítor Matias Ferreira refere, a propósito de Lisboa, que a cidade se dá a ver através de uma complementaridade de "distintos planos de observação, diferentes escalas de leitura e de vivência" (2004: 383); Jean-Marc Stébé e Hervé Marchal abrem a recente e muito completa colectânea intitulada Traité sur la ville, com a proposta decidida de "tratar" a cidade em todas as suas dimensões e "estados" (2009: 5-39); o que significa que formas de colaboração trans-disiciplinares são cada vez mais imprescindíveis e que a etnografia, com o seu múltiplo enraizamento disciplinar, é cada vez mais necessária para descobrir a cidade mais próxima das vivências concretas dos seus habitantes e visitantes.

10 Tradução livre. 


\section{Bibliografia}

AGIER, Michel, 1996, "Les savoirs urbains de l'anthropologie", Enquête, 4: 35-58.

AGIER, Michel, 1999, L'invention de la ville. Banlieues, townships, invasions et favelas, Amesterdam: Editions des Archives Contemporains.

AGIER, Michel, 2008, “O acampamento, a cidade e o começo da política" in Cordeiro, Graça e Frédéric Vidal (org) A rua. Espaço, tempo, sociabilidade, Lisboa: Livros Horizonte, 17-25.

AGIER, Michel, 2009, Esquisses d'une anthropologie de la ville. Lieux, situations, mouvements. Louvain-la-Neuve: Academia-Bruylant.

BARNES, John A. 1954, "Class and Committees in a Norwegian Island Parish", Human Relations, 7: 39-58.

CORDEIRO, Graça Índias, 1987, Laranjïnha, lazer, solidariedade: um ensaio de antropologia urbana, Dissertação de Mestrado, F.C.S.H. - U.N.L.

CORDEIRO, Graça Índias, 1997, Um lugar na cidade. Quotidiano, memória e representação no bairro da Bica. Lisboa: Dom Quixote.

CORDEIRO, Graça Índias, 2003 “A antropologia urbana entre a tradição e a prática” in Cordeiro, Graça I. , Luís. V. Baptista e António F. Costa (org) Etnografias Urbanas, Oeiras: Celta, 3-32.

CORDEIRO, Graça I e Frédéric Vidal, 2008 A rua. Espaço, tempo, sociabilidade. Lisboa: Livros Horizonte.

COSTA, António Firmino, 1999, Sociedade de Bairro. Dinâmicas Sociais da Identidade Cultural, Oeiras: Celta.

EAMES, Edwin; Goode, Judith Granich, 1977, Anthropology of the city. An introduction to Urban Anthropology Englewood Cliffs, New Jersey: Prentice-Hall.

EVANS-PRITCHARD, Edward., 1940 The Nuer, Oxford: Clarendon Press.

FERREIRA, Vítor Matias, 2004, Fascínio da Cidade. Memória e projecto da urbanidade, Lisboa: Ler Devagar.
FOX, Richard, 1972 "Rationale and Romance in Urban Anthropology", Urban Anthropology, 1: 205-33

GULICK, John, 1989, The humanity of cities. An introduction to urban societies Granby, Massachusetts: Bergin and Garvey Publishers, Inc.

HAMEL, Jacques, 1997, Étude de cas et sciences sociales, Paris: Harmattan.

HANNERZ, Ulf, 1980, Exploring the City. Inquiries toward an Urban Anthropology, New York: Columbia University Press.

LEEDS, Anthrony 1978 (1964), "Poder local em relação com instituições de poder supra-local" in A. Leeds e E. Leeds A sociologia do Brasil urbano, Rio de Janeiro: Zahar Editora, pp. 26-54.

MAGNANI, José Guilherme Cantor, 2002, "De perto e de dentro: notas para uma etnografia urbana", Revista Brasileira de Ciências Sociais17 (49):11-29.

MARCHAL, Hervé, 2009, "Identité citadine" in Stébé, JeanMarc e Hervé Marchal, 2009 Traité sur la ville, Paris: PUF.

RIBEIRO, Orlando, 1963, “Aldeia”, Dicionário da História de Portugal, Porto, Iniciativas Editoriais, vol. 1.

SIGNORELLI, Amalia, 1999 (1996), Antropología Urbana, Barcelona: Anthropos.

STÉBÉ, Jean-Marc e Hervé Marchal, 2009, Traité sur la ville, Paris: PUF.

VALENTINE, Charles, 1972, La cultura de la probreza, Buenos Aires: Amorrortu.

VELHO, Gilberto, 1981, Individualismo e cultura. Notas para uma Antropologia da sociedade contemporânea, Rio de Janeiro: Zahar Editores.

VELHO, Gilberto, 1994, Projeto e Metamorfose. Antropologia das Sociedades Complexas, Rio de Janeiro: Jorge Zahar Editor.

WEBER, Florence 2009, Manuel de l'ethnographe, Paris: PUF. 